\title{
Reader-Response Approach to On-Line Collaborative Translation of Popular Literatures in China
}

\author{
XU Huiyan \\ School of Law and Humanities, China University of Mining and Technology, Beijing
}

\begin{abstract}
This paper mainly analyses the on-line collaborative translation of popular literatures taking the translations of Harry Potter as an example. Based on the transactional reader-response theory and social reader-response theory, it discusses the transaction among source text, target text, source text reader and target text reader, and examine different critical camps/readers and their different interpretative strategies to the text so as to obtain a more objective perception of the on-line literary translation. It is concluded that translators and readers should join hands in actively making the meaning of the source text, and the interaction between the two texts and two readers is a very significant translating process, which greatly helps improve the quality of the final version.
\end{abstract}

Key words: reader-response theory, on-line collaborative translation, source text and target text, source readers and target readers

\section{INTRODUCTION}

Internet, with its dynamic, timely and interactive features, has expanded the channels of the cross-cultural communication and reading, and also motivated the emergence of on-line translated literature, which greatly contributes to the prosperity of literary translation in China.

What is on-line translated literature? First, we need to clarify the difference between literary translation and translated literature. The former, opposite to non-literary translation, is a type of translation whose objectives are literary works from different countries, while the latter is the collection of all the literary works translated into Chinese.

Zhang $\mathrm{Xu}$ (2002) makes a further distinction between networking-translated literature and on-line translated literature.

The former refers to the transference of original translation of literary works to the internet featured in linked hypertexts to allow readers to read and download, while the latter is a new kind of literature form produced with the help of computer and internet, including the direct translation from the computer software and internet, and cooperation between human translator and machine translating (17).

There is another one mentioned by Cao \& Zhao, that is, the collaborative translation of on-line translators with the help of internet (132).

Based on the above classifications, this paper mainly analyses the on-line collaborative translation of popular literatures with reader-response theory, taking the translations of Harry Potter as an example.

\section{ON-LINE COLLABORATIVE TRANSLATION IN CHINA}

Internet opens a door to the world, making collaboration possible. There are three famous translating groups in China. One is the Eco Team who has translated more than 8,000 articles from British news magazine The Economist since 2006. Members collaborate with the translations, posting articles on their message board to be collectively copy-edited. The final versions are published on Eco Weekly a biweekly publication that can be downloaded and printed at no cost (Farrar n.p.). The other is the team on yeeyan net in which a slogan is very inspiring: "Collaboration: You are not the only worker." This collaborative team has translated some news articles from The Boston Global, Business Week, New York Times, New Yorker, and Atlantic Monthly, aiming at introducing to Chinese readers something about the outside and also outsiders' opinions about China. They usually translate some hot topics.

The third one is the translation groups of Harry Potter taking the Houlee8 or baidu as their main forums, which actually starts from the translation of Harry Potter 5. At that time, Potter fans can't wait to know the plot of the story, and even some were not satisfied with the official translation of Harry Potter (1-4), so they started to translate it by themselves. By the time of translating Harry Potter 6 in 2005 , on-line literary translation has become more mature and gained high popularity and special concerns from the traditional media (Zhang 15). However, the greatest on-line translation occurred on July 232007 . Three days after the issue of English version of Harry Potter 7, a translating team called "Harry 7 or Hogwarts translation school" consists of 60 translators collaboratively finished its on-line Chinese version, satisfying the demands of anxious readers, while the authorized People's Literature Publishing House is scheduled to publish its version 3 months later (Chen 105).

On-line collaborative translation has aroused a wide concern not only from China but also from American media. In 2005, Kang Kai published an article "Has the Age of People's On-Line Translation Arrived?" It started with a report about the competition between People's Literature Publishing House (authorized publisher of Harry Potter in China) and on-line translators. When the entrusted translators have just started their work, many other unauthorized individual or collaborative versions have been published on the Internet, about 2 months ahead of the schedule of the publishing house. Actually, such kind of on-line translation is not only limited to Chinese, but also to Russian and 
German. This results from the anxious expectations of the Harry fans on the one hand, and the convenient and quick platform the internet provides on the other (n.p.).

Another article published in CNN.com (16 June 2009) by Lara Farrar also introduced such on-line translating teams who are called China's volunteer online army in translation.

Those translators are voluntary and are translating a mix of media, from books and magazines to games, TV shows and movies....The members of these online translations groups participate out of a desire to improve their English. For many there is also a passionate interest in overseas content and a desire to make it accessible to other Chinese people (n.p.).

\section{READER-RESPONSE CRITICISM}

According to Lois Tyson (2006), reader-response theory has five categories: transactional reader-response theory, affective stylistics, subjective reader-response theory, psychological reader-response theory, and social readerresponse theory. But those approaches are not clearly divided, with some overlapping in the final analysis (172) .

They share two beliefs: (1) the role of the reader is very important to our understanding of the text and (2) readers actively make the meaning of the text instead of passively consume it. Reader-response theorists believe that different readers may read the text differently, and even the same reader reading the same text on two different occasions will probably produce different meanings due to different experiences (170).

This paper mainly employs the approaches of transactional reader-response theory and social readerresponse theory. The first one is formulated by Louise Rosenblatt, with a focus on the analysis of the transaction between text and reader, claiming that the responses from our feelings, associations and memories occur as we read will influence the way of understanding or making the meaning, but the text will act as a blueprint to correct our interpretation (173). The second one is mainly related to the later work of Stanley Fish, who believes that our individual subjective responses to literature are really products of the interpretive community with predisposed interpretive strategies (185) .

Therefore, it is necessary to analyze the transaction between text and reader, and examine different critical camps/readers and their different interpretative strategies to the text so as to obtain a more objective perception of the online literary translation.

\section{SOURCE TEXT, TARGET TEXT, TRANSLATOR AND READER}

It is generally known that translating is a complex communication between language and culture, and an open process of interaction among the translator, the text and reader, involving reading and writing skills, the choice of text, its reproduction and dissemination, in which the reader plays an irreplaceable role. Translator is the reader of the source text and also the writer of the translation, while the reader of the translation is not only the receiver but also the critic and even the writer of the new translation. Thus, there are at least two texts (source text and target text), two readers (reader of the source text and reader of the target text). All of these two readers' responses to the two texts will contribute to the final translation. For convenience, the author uses text 1 and reader 1 for the source text and translator, while text 2 and reader 2 for the target text and the reader of the translation.

\section{TRANSACTION BETWEEN THE TEXT 1 AND READER 1}

A good translation must be faithful to the text 1 . However, in the translating process, a translator's experience will inevitably affect his/her understanding of the text 1 , leading to correct or wrong interpretations. As for the on-line collaborative translation, this problem is obviously prominent. At the same time, it can't be denied that some online translators translate the work for fun or pleasure, leading to some poor versions. For example, there is a collaborative version of Harry Potter 6 by 9 translators with net names and 3 anonymous translators. Due to the limited time and quick speed, and the collaboration of 12 translators, their translation style is not in conformity with some dialectics and colloquial expressions from Northeastern and Southern China (Lu 32).

However, most of on-line translators take very serious attitudes to the source text. Take the Harry 7 team for an example. Wang, the head of team, told the journalist that they translated the work out of obligations to allow Harry fans to read as soon as possible. In fact they had downloaded the English WORD version of Harry Potter 7 on July 18, 2007, but they waited until July 21, the date of initial global issue in order to respect the original work. They started to recruit translators from July 2 and finally selected 60 translators based on their translation of a given passage related to Harry Potter found in western reports. Among 60 translators, about 20 are high school students, especially those finished college entrance examination, but most of them are college students. And then they assigned work and schedule, basically 4-5 translators in a group. In order to guarantee the quality, each chapter was produced in four phases: translation, revision, proof reading and final review. Besides, their e-version was signed with the net name or ID of the translator, reviser and final editor. It is proved that the translation of Harry 7 team is the most popular one then $(\mathrm{Xu}$ n.p.).

According to an on-line translator of Harry Potter 7 in July 2007, at that time, the translation and discussion are fully done on the internet, with QQ, MSN flashing from all over the world, including Sweden and Canada, there are always translators worked till midnight and others continued their works due to the different jet lag. People talked day and night with chat records over 1 thousands a day (Chen 105).

Here, we can see that on-line translators are actively making the text 2 based on their transactions with the text 1 and other translators. 


\section{TRANSACTION AMONG THE TEXT 2, READER 1 AND READER 2}

In the world of on-line translation, there is no authority and everyone has a say. On the one hand, readers can access the source text and read with the help of translation software or tools, so they can give more specific responses. What's more, they can criticize anonymously, in this way they can give more objective and true reactions. Therefore, on-line translators have to work hard and carefully in order to win over the readers (Chen 106). On the other hand, on-line readers act as the referee. They sometimes evaluate the translation based on the amount of clicks and download, and decide who the best translator is. For example, according to the readers' response, a translator named Blimey, a university student of science major in Beijing University, gained the highest reputation (Zhang n.p.).

On-line translation also allows readers to involve actively and synchronically with the translators. Most of readers' comments are encouragements and praises like "well done; thank you," offering spiritual support to translators and promote them to produce better versions. However, on-line readers are not passive receivers. Some of them took very seriously about the translation.

For example, a reader pointed out the difference in the versions of Blimey and others concerning the sentence, "and when she finally bowed them out of the shop it was with an air of being glad to see the back of them." Some translated "the back of them" into "the return of harmonious air of the shop", while Blimey rendered it into "glad to see that they are gone." To this response, Blimey replied that his understanding is right because "back" here refers to "the figure viewed from behind." (Zhang n.p.)

For another example, in the on-line translation of chapter 3 of Harry Potter 6, a reader pointed out the misunderstanding of the relation between Sirius. Black and Bellatrix Lestrange, translating the latter into biaojie (elder female cousin of mother's side), but in fact it should be tangjie (elder female cousin of father's side). Finally, after the communications, tangjie was adopted in the complete Chinese version published on internet ( $\mathrm{Lu} \mathrm{10)}$.

Besides, on-line translators are not only translators but also peer critics. For example, an on-line translator $\mathrm{H}$ is not satisfied with another translator Laohe's translation of the title of Chapter six "The Noble and Most Ancient House of Black", challenging the word meaning of "house" here. The former is translated into "family", while the latter "dwelling". (n.p.)

The above examples show that translators and readers join hands in actively making the meaning of the source text, and the interaction between the two texts and two readers is a very significant translating process, which greatly helps improve the quality of the final version.

\section{DIFFERENT INTERPRETATIVE COMMUNITIES}

To the on-line literary translation, the responses in China vary from positive, negative attitudes to objective/neutral opinions. For example, some translation experts express their affirmation and admiration to such phenomenon, claiming that this kind of translation should be advocated because it is done for interests not for profits (Lin n.p.). However, negative critics claim that on-line translators often move beyond the source text and create a channel to take out their desires, thus the translation quality can't be guaranteed (Cao \& Zhao 133).

Neutral/objective one often questions the quality of on-line translators and their translations, concerns about the on-line copyrights, the influence on the official translation, and misuse by the illegal publishers. For example, Kang Kai (2005), a journalist expresses his concerns about the on-line translation, saying that no any writer would like to give his/her works to a translator with anonym or just net names except those fans. And besides, there will be no serious readers to treat the translation seriously. Therefore, creation, translation, publication and reading are a serious process which can't run smoothly in a mess (n.p.).

Zhang Xu (2002) sums up three types of readers in academic field:

The first group of readers are promoters of on-line translated literature. They are usually young readers (born in 1960-70's or so) who actively involve in on-line translation and publish inciting remarks to applaud such a new phenomenon, or to deride those far behind the network culture. The second group is middle-aged network researchers (born in about 1950's) who tend to judge fairly and objectively on the positive or negative effects of on-line translations and at the same time express their concerns and worries about the quality of the translators and translations, and the causality of on-line translation. The third group is those professional scholars, especially born in 1940's, who reject it based on the traditional translation criteria of faithfulness, smoothness and elegance and, therefore, negatively evaluate the on-line translation (18-9).

Actually, in terms of on-line translation of Harry Potter, there are another two important groups of readers (born after 1980-1990's) who are all the fans of Harry Potter. One is the middle school students who focus their attention on the plot of the story, so they would like to embrace any kind of translation as long as it can satisfy their curiosities and desires, and the other is high school or college students who either actively participate in the translation, or voice their evaluations and assessments of the other's versions. Both groups are direct consumers of those on-line translations, and especially the second group of readers' response can't be neglected because they are more familiar with the novel and also have the ability to read and translate the novel.

The reason why there are so divided views among readers is that these readers have different personal background, different education, age, and experiences. Such stratification of readers is also made according to the different interpretive communities to which they belong to and different interpretive strategies they use.

For example, the first group belongs to 30-40 year-old reader community who can easily accept new things and sometimes act on passion and enthusiasm; they tend to analyze the text based on their own experience and evaluation. The second group is those in the age of 50 plus. 
Since they are more mature in thinking and profession, they tend to judge about the new things in a more comprehensive way. The third is those over 60-year old scholars who stick to the traditional concept and idea, considering it unbelievable that everyone can be a translator, thus they have deep doubts about the translation quality. The last two groups are much younger, but they are in the front of new technology and full of curiosity and long for the involvement, the pursuit of something new and sensational, so they can put forward either positive or negative responses out of their knowledge background.

\section{CONCLUSION}

To conclude, on-line collaborative translation has become a trend, and will certainly rewrite traditional literary translation, naturally bringing a lot of opportunities and challenges to translators, readers, and official publishers. The transaction between the two texts and two readers can't be ignored because it helps continue the after-life of the source text. In spite of their divergent criticisms of different levels due to their different interpretive communities and strategies, on-line readers will provide a multi-perspective and wider vision to the translation. Just like Chinese translation theorist $\mathrm{Xu}$ Jun said, "In term of translation, it is promising for the translation of a work to receive responses and discussions from readers, and to involve common readers in caring for the translation quality and problems. This is the hope brought by the net era to the literary translation, which will greatly promote the development of translation field (Tian n.p.).

\section{REFERENCES}

[1] Fan, Xu. "Investigation into Unofficial Translation Army of Harry Potter 7 with $30 \%$ of High School Students." Youth Weekend. 26 July 2007. Web. 6 May 2011.

[2] Farrar. Lara. "Found in Translation: China's Volunteer Online Army." CNN.com. June 16, 2009. Web. 5 May 2011.

[3] Jiangxian, Lin. "Copyrights Concerning On-line translation of Harry Potter 6." New365.com. 27 July 2005. Web. 6 May 2011.

[4] Jun, Xu. "Internet and Literary Translation Criticism." Foreign Language Teaching and Research 38.3 (2006):216-7. CNKI. Web. 6 May 2011.

[5] Kai Kang. "Has the Age of People's On-Line Translation Arrived? With Harry Potter 6 As Example.” China Reading Weekly. 23 Aug. 2005. Web. 5 May 2011.

[6] Kan, Lu. "On-line Translation with Harry Potter 6 As an Example." Dissertation. Shanghai International Foreign Studies, 2007. Print.

[7] Peng, Cao \& Zhao Yanli. "The Translated Literature in the Net-Era." Journal of the Party School of CPC Zhengzhou Municipal Committee 79.1 (2006): 132-3. CNKI. Web. 3 May 2011.

[8] Shougang, Zhang. "Self-Translations of Harry Potter (6) with Different Styles Competing on Internet." Beijing Star Daily. 1 Aug. 2005. Web. 6 May 2011.

[9] Tyson, Lois. Critical Theory Today: A User-Friendly Guide, 2nd edition. New York: Routledge, 2006. Print.

[10] Yanqin, Zhang. "Diverse Roles of Readers in Literary Translation in the Internet Era." Journal of Guangdong University of Foreign Studies 18.6 (2007):15. CNKI. Web. 1 May 2011.

[11] Yi, Chen. "The Synchronic Character of Internet Translation." Journal o f Gansu Lianhe University (Social Sciences) 25.2 (2009): 105-6. CNKI. Web. 6 May 2011.

[12] Yupeng, Zeng. "On-line Version of Harry Potter Challenges Publishing House.” Beijing Youth Daily. 29 July 2003. Web. 5 May 2011.

[13] Xu, Zhang. On On-line Translated Literature. Comparative Literature in China 2(2002): 16-22.

[14] Zhiling, Tian. "The Embarrassment of Lord of the Rings and the Crisis of Literary Translation.” Nanfang Daily. 24 Aug. 2005. Web. 5 May 2011. 